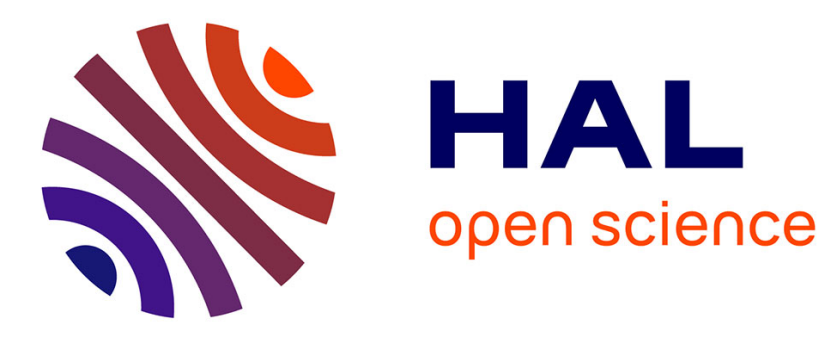

\title{
Film formation mechanism in glass lubrication by polymer latex dispersions
}

\author{
Muriel Beauvais, Piezel Benoît, Farid Hamidi, Mélanie Villalobos, Claude da \\ Silva, Eric Martin, Davy Dalmas, Etienne Barthel
}

\section{- To cite this version:}

Muriel Beauvais, Piezel Benoît, Farid Hamidi, Mélanie Villalobos, Claude da Silva, et al.. Film formation mechanism in glass lubrication by polymer latex dispersions. Thin Solid Films, 2010, 518 (6), pp.1689-1697, TSF-26981. 10.1016/j.tsf.2009.11.061 . hal-00444094

\section{HAL Id: hal-00444094 \\ https://hal.science/hal-00444094}

Submitted on 5 Jan 2010

HAL is a multi-disciplinary open access archive for the deposit and dissemination of scientific research documents, whether they are published or not. The documents may come from teaching and research institutions in France or abroad, or from public or private research centers.
L'archive ouverte pluridisciplinaire HAL, est destinée au dépôt et à la diffusion de documents scientifiques de niveau recherche, publiés ou non, émanant des établissements d'enseignement et de recherche français ou étrangers, des laboratoires publics ou privés. 


\title{
Film Formation Mechanism in Glass Lubrication by
}

\section{Polymer Latex Dispersions}

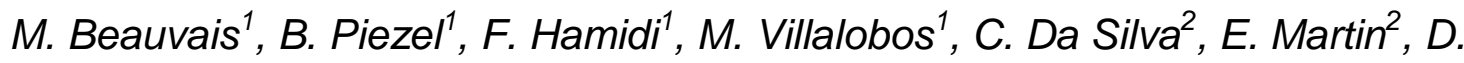 \\ Dalmas ${ }^{1}$, E. Barthel ${ }^{1}$
}

${ }^{1}$ Laboratoire Surface du Verre et Interfaces, UMR 125, CNRS/Saint-Gobain, 39 quai Lucien Lefranc, B.P. 135, F-93303 Aubervilliers cedex, France

${ }^{2}$ Saint-Gobain Recherche, same address.

Corresponding author: M. Beauvais, e-mail address: muriel.beauvais@saintgobain.com

\section{Abstract}

The stabilization of organic coatings by tin dioxide resulting in glass bottle lubrication was investigated on flat glass. The anchoring function of $\mathrm{SnO}_{2}$ was assessed for a mixture of polyethylene and polymethylmethacrylate. Friction tests in air confirm the $\mathrm{SnO}_{2}$ anchoring property with the maintaining of the lubricant effect due to the polymer over large sliding distances. The persistence of the polymethylmethacrylate stretching band $v_{C=O}$ on significant sliding distances in infrared microscopy experiments shows that the polymer coating stabilization results from the strong adhesion of the polymer on $\mathrm{SnO}_{2}$. The impact of roughness and surface chemistry on the stabilization of the polymer coating was tested. The 
suppression of the lubricant effect by surface chemistry alteration or by roughness modification of $\mathrm{SnO}_{2}$ suggests that roughness and surface chemistry of $\mathrm{SnO}_{2}$ are both necessary for lubrication.

Keywords: glass, lubrication, $\mathrm{SnO}_{2}$, roughness, surface chemistry, polymer.

\section{Introduction}

Surface flaws generated by sliding contacts between glass bottles on production lines and transport affect both their mechanical strength and visual aspect. To improve their scratch resistance and prevent surface damage, glass bottles are subjected to two successive surface treatments. The first one, called "hotend coating", is a vapour phase deposition at atmospheric pressure of a thin oxide film while bottles are at elevated temperature in the range 520-650 $\mathrm{C}$. The oxide coating maintains the high pristine strength of glass [1,2]. Tin dioxide is currently used industrially for its high transparency to visible light and high hardness and is deposited from organometallic precursors such as tin tetrachloride $\left(\mathrm{SnCl}_{4}\right)[3,4]$ or monobutyltintrichloride $\left(\mathrm{n}-\mathrm{C}_{4} \mathrm{H}_{9} \mathrm{SnCl}_{3}\right)$ [5-9]. The second one, called "cold-end coating", consists in a spray deposition of an organic water-based formulation (polyethylene, waxes, oleic acid ...) at bottle temperatures between $80^{\circ} \mathrm{C}$ and 160 ${ }^{\circ}[10,11]$. The organic layer is stabilized by the oxide resulting in lubrication and surface damage prevention $[1,4,11]$. The metal oxide film is reported to act as an anchor or primer for the organic coating to the glass surface container $[1,12]$. There are two possible explanations to organic layer stabilization. The anchoring function of the primer would originate from its ability to increase the bond strength of organic coatings to the glass. This assumption is based on an overview by Smay [13] about the nature and strength of interactions between organic adsorbates and glass 
surfaces or oxides. The author concludes about the existence of stronger Brönsted acid sites and strong Lewis acid sites due to the metallic cations which explain why they interact with polar and nonpolar organic molecules more strongly than sodalime silica glasses. The stronger acid-base interactions between the primer and the polymer also result from the cation polarisability of oxides. Glass surfaces interact strongly with organic molecules only if they possess highly polar functional groups. The more covalent character of tin dioxide determined by surface energy measurements of bare soda-lime silica glass and $\mathrm{SnO}_{2}$-coated glass supports this assumption [14]. Microextraction experiments of cold-end coatings such as modified polyethylene from $\mathrm{SnO}_{2}$-coated glass containers suggest that the organic layer is firmly anchored to the primer, but the existence of a polymer- $\mathrm{SnO}_{2}$ interface chemistry is not evidenced [11].

Many efforts have been made to optimize the scratch resistance or the internal bursting pressure of glass bottles. Optimal mechanical properties are mainly reported as a function of a combination of tin dioxide thickness and quantity of deposited polymer $[1,4,10,15]$. However, the glass surface is roughened by the tin dioxide deposit $[16,17]$, and the anchoring function of the primer would also be mechanical in nature as suggested by Pantano et al. [16]. Moreover, a rise of the primer roughness leads to an increased deposition of polymer and the oxide morphology also changes with its thickness $[15,18]$.

From these observations and results, the roles of surface chemistry, roughness and morphology in the anchoring function of the primer remain unclear. The purpose of this work is to understand why the $\mathrm{SnO}_{2}$ primer is able to anchor the organic layer: are the morphology and roughness of the primer responsible or does the organic layer- oxide interface chemistry play a role? Moreover, concerning the 
role of roughness in lubrication, could glass without primer also be able to act as an anchor for the polymer coating with an appropriate roughness?

The present paper is divided in two main parts. The first one is devoted to the evaluation of the anchoring function of the primer for the polymer coating. The primer is a rough tin dioxide deposited on flat glass by chemical vapour deposition (CVD) and the polymer is a mixture of polyethylene (PE) with a dispersion of polymethylmethacrylate (PMMA) spheres. Such a coated glass is considered as a reference in this study. The scratch resistance of the $\mathrm{SnO}_{2}$-coated glass is quantified through friction tests in air on a reciprocating ball-on-plate tribometer and is compared to that without primer after the polymer deposition. To understand the stabilization phenomenon of the organic layer by the primer, wear tracks resulting from friction on polymer-coated glass and polymer- $\mathrm{SnO}_{2}$ coated glass were analyzed by infrared microscopy to follow the presence of the polymer. The wear tracks were also characterized by Nomarski optical microscopy and atomic force microscopy (AFM) in air to investigate the impact of the primer on the evolution of the polymer morphology due to the compressive and shear stresses. The second part is dedicated to the role of surface chemistry and roughness of the primer in the organic layer stabilization. The postulated mechanical anchoring of the polymer by the primer due to an increase in the surface roughness after the primer deposition on glass is evaluated with smoother tin dioxides deposited on flat glass as well as with a flat glass whose surface is roughened by a silica coating deposition. To suppress the strong acid-base interactions between the primer and the polymer, a thin silicon nitride layer is deposited on the rough $\mathrm{CVD} \mathrm{SnO}_{2}$ while preserving the original roughness of the primer. The scratch resistance of such coated glasses is quantified and compared to that of the rough primer after the polymer deposition. 
The study shows that the enhanced scratch resistance of the polymer-coated $\mathrm{SnO}_{2}-\mathrm{CVD}$ film on glass is due to the strong adhesion of the polymer to the primer, as revealed by the persistence of the PMMA stretching band $v_{C=O}$ over large sliding distances. Good wetting results in well dispersed PMMA spheres on the surface and the strong adhesion leads to the formation of a continuous organic film under the mechanical stress by coalescence of flattened spheres. Moreover, the results suggest that the roughness and the surface chemistry of the primer are both necessary to the glass bottle lubrication. The large plastic deformation of PMMA spheres results from the combination of the surface roughness sharpness and shear due to strong adhesion.

\section{Experimental}

\subsection{Methods}

\subsubsection{Friction experiments}

Friction tests were performed on a reciprocating ball-on-plate tribometer (Plint T79) with a fused silica sphere as the ball specimen in ambient air. All experiments were carried out with an initial Hertz mean pressure Pm close to $450 \mathrm{MPa}$ (i.e. a normal load $F_{N}$ of $9 \mathrm{~N}$ and a mean diameter of the ball specimen of $5.5 \mathrm{~mm}$ ). Under these conditions, the theoretical contact width is $155 \mu \mathrm{m}$. Sliding velocity and length were fixed at $1 \mathrm{~mm} / \mathrm{s}$ and $8 \mathrm{~mm}$ respectively. The ball specimens were made from silica rods (Won Ik Quartz) by melting the extremity with a blowtorch until a molten droplet of glass formed. Silica spheres were cleaned in an ultrasonic bath using four successive sequences of 15 min, respectively in detergent, distilled water, acetone and absolute ethanol and irradiated for $1 \mathrm{~h}$ by a UV-Ozone flow. Friction tests were carried out immediately after the silica ball cleaning and the polymer deposition on 
flat glasses to minimize surfaces contamination. The friction force $F_{T}$ between counterparts was averaged over each cycle ( 1 cycle corresponds to a cumulative sliding distance of $16 \mathrm{~mm}$, i.e. one back and forth carried out by the silica sphere). Each experiment was repeated at different locations on the surface (at least four) with a new silica ball. The mean value of the friction coefficient $\mu$, defined as the ratio $F_{T} / F_{N}$, is reported as a function of the cumulated sliding distance of the ball specimen in a test.

\subsubsection{Surface imaging and roughness characterization}

The coatings morphology was examined prior to friction tests with a Digital Instruments Nanoscope III atomic force microscope in air. Surfaces were scanned in tapping mode at a resolution of $512 \times 512$ pixels, with a silicon nitride tip having an estimate stiffness of $0.06 \mathrm{~N} \cdot \mathrm{m}^{-1}$. The RMS roughness $R_{r m s}$ of inorganic coatings was calculated from AFM images analysis using the Nanoscope III software. For each coating, $R_{r m s}$ was averaged from three different measurements over scanned areas of $1 \mu \mathrm{m}^{2}$. AFM in tapping mode was also used to follow the impact of the CVD primer on the evolution of the organic coating morphology due to compressive and shear stresses. Scans were performed at different locations in wear tracks as a function of the cumulated sliding distance of the ball specimen in the test. Only half of each track from the edge to the center was characterized owing to the symmetric distribution of pressure in the contact as predicted by Hertz for a static ball-on-flat elastic contact [19]. Scans were conducted in such a way that half tracks were completely imaged. The coatings morphology was also examined by scanning electron microscopy (SEM) (inorganic coating) and by differential interference contrast microscopy (Nomarki optical microscopy)(organic coatings and wear tracks). 


\subsubsection{Infrared microscopy}

Wear tracks on polymer-coated $\mathrm{SnO}_{2} \mathrm{CVD}$ films and polymer-coated glass were analyzed by infrared microscopy to follow the presence of polymer on surface. The carbonyl stretching band of PMMA $\left(v_{C=0}\right)$ centered at $1729 \mathrm{~cm}^{-1}$ and the stretching bands of PE $\left(v_{\mathrm{CH}}\right)$ at $2920 \mathrm{~cm}^{-1}$ and $2850 \mathrm{~cm}^{-1}$ were selected. Their intensity was reproducible at different locations on the undamaged coatings and thus could be compared to the $v_{C=O}$ and $v_{C H 2}$ intensities detected in wear tracks. These comparative measurements made it possible to follow the variation of the amount of polymer due to the mechanical stress. Measurements were performed at two different locations in each track, as a function of the cumulated sliding distance. Such a technique couples a conventional optical microscope to a Nexus spectrometer in reflexion mode. The optical visualisation of surfaces after wear and the use of a mask having a rectangular slit to only select wear tracks provided infrared absorption data from an area of $120 \mu \mathrm{m} \times 850 \mu \mathrm{m}$. Spectra were taken at a resolution of $4 \mathrm{~cm}^{-1}$ for 512 scans with unpolarized light.

\subsubsection{Polymer deposition}

Prior to polymer deposition, the coated glasses were cleaned in an ultrasonic bath using two successive sequences of $10 \mathrm{~min}$, respectively in absolute ethanol and distilled water. The glass without primer was irradiated for $1 \mathrm{~h}$ by a UV-Ozone flow after cleaning in the ultrasonic bath. The organic layer was deposited on the glass plates by dip-coating in laboratory, using a withdrawal speed of $50 \mathrm{~mm} / \mathrm{min}$. This procedure avoids the heterogeneous polymer distribution observed on the surface when sprayed in the factory. The organic deposition was followed by a heat treatment at $120^{\circ} \mathrm{C}$ for $10 \mathrm{~min}$ to match with the industrial d eposit temperatures on bottles. 


\subsection{Materials}

\subsubsection{Polymer emulsion}

A diluted dispersion of PMMA spheres and PE in water was chosen. Such a polymer mixture is commonly used in cold-end treatment of glass bottles. The size distribution of PMMA spheres in the emulsion is narrow and centered around $100 \mathrm{~nm}$, as determined by dynamic light scattering.

\subsubsection{Substrates for the polymer coating}

Different substrates for polymer deposition were used. The film thickness was evaluated by X-ray reflectometry or SEM. Designation and characterizations are as follows: (see Table 1 for justification)

(1) Glass: commercial flat soda-lime silica glass having the same $\mathrm{Na}_{2} \mathrm{O}$ content as in the bottle glass.

(2) $\mathrm{R}-\mathrm{SnO}_{2}$ : CVD of tin dioxide $\mathrm{SnO}_{2}$ on (1), performed on site on a production line of glass bottles at a homogeneous glass surface temperature of $570{ }^{\circ} \mathrm{C}$ with the same deposition parameters used for glass bottles. The coating is crystallized [20] and has a thickness of a few tens of nanometres, in the range of the usual $\mathrm{SnO}_{2}$ CVD film thicknesses on glass bottles [10].

To modulate the roughness and surface chemistry of the substrate for the polymer coating, reactive d.c. magnetron sputtering of amorphous inorganic coatings were carried out in the laboratory. The substrate holder temperature was maintained at $25^{\circ} \mathrm{C}$ during the deposition. These inorganic coa tings consisted in:

(3) $\mathrm{S}-\mathrm{SnO}_{2}$ : tin dioxide on (1), with a thickness of $5 \mathrm{~nm}$.

(4) $\mathrm{r}-\mathrm{SnO}_{2}$ : same as (3) followed by annealing at $570{ }^{\circ} \mathrm{C}$ durin $\mathrm{g} 5 \mathrm{~h}$ for crystallisation [20]. 
(5) R-SiO 2 : silica on (1), with a thickness of $475 \mathrm{~nm}$.

(6) $\mathbf{R}-\mathrm{Si}_{3} \mathbf{N}_{4}$ : silicon nitride on (2), having a thickness of $5 \mathrm{~nm}$.

\subsubsection{Morphology and roughness of substrates for the polymer coating.}

$R_{r m s}$ roughnesses are reported in Table 1.

(1) Glass: typical defects of float glass surface (rings) are present and randomly distributed [17]. Their height does not exceed $0.8 \mathrm{~nm}$ and controls the $R_{r m s}$ roughness.

(2) $\mathrm{R}-\mathrm{SnO}_{2}$ : the glass surface has been roughened by the $\mathrm{SnO}_{2} \mathrm{CVD}$ deposit, in agreement with the observations of Pantano et al. $[16,17]$. The coating is rough and structured due to discrete facetted grains whose average size is close to $27 \mathrm{~nm}$ (Fig. $1 a-b)$. The discrete facetted oxide grains lead to the sharp variation of heights of the AFM section profile (Fig. 1c). The film is also characterized by empty volumes or holes (black features) which are randomly distributed (Fig. 1a). Hole depth is of the same order of magnitude as the coating thickness, i.e. a few tens of nanometres. These features are also present on $\mathrm{SnO}_{2}$-coated glass bottles [16,21]. They are created by the dissolution of the sodium chloride crystals formed during the deposition [21,22], when bottles are annealed and cold-end coated.

(a)

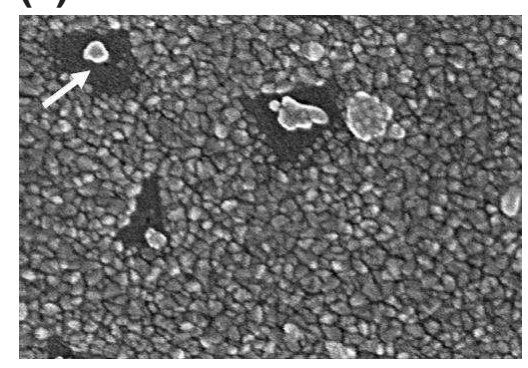

(b)

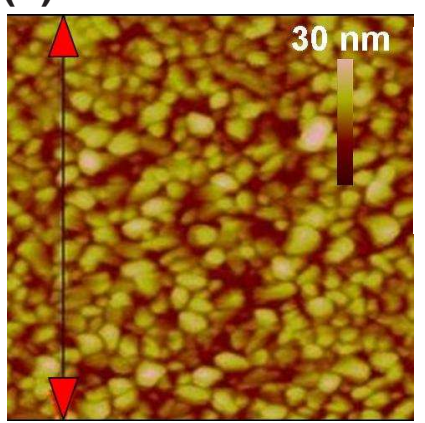

(c)

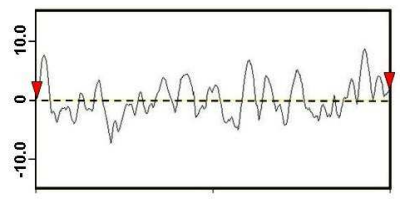

Fig. 1. R-SnO ${ }_{2}$ morphology (a) SEM image: holes are present in the coating (cf. arrow) (b-c) AFM image $\left(0.25 \mu \mathrm{m}^{2}\right)$ and corresponding section profile. 
(3) $\mathrm{S}-\mathrm{SnO}_{2}$ : the sputtering of a thin tin dioxide layer on glass results in a smooth primer which has no particular structure but the ring defects of glass are still visible owing to the small oxide coating thickness (Fig. 2a-b). Their height does not exceed $0.8 \mathrm{~nm}$ (Fig. 2c) and the rings control the coating roughness.

(b)

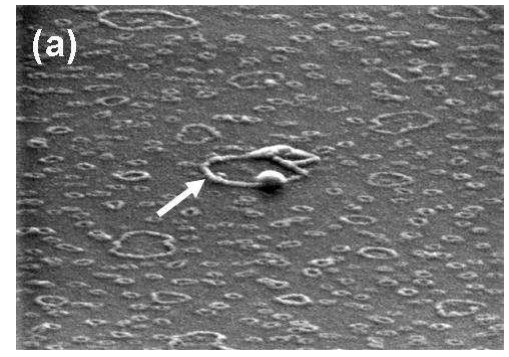

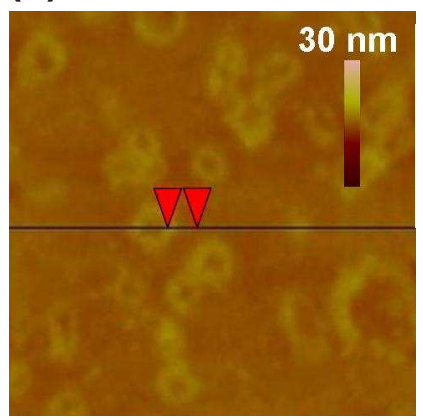

(c)

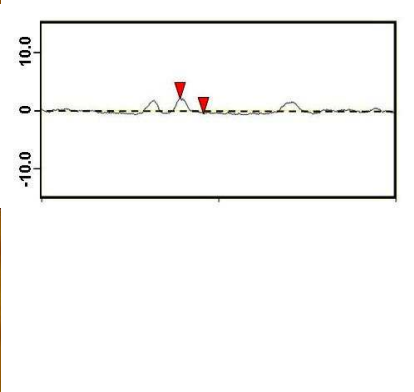

Fig. 2. S-SnO 2 morphology (a) SEM image of a tilted section of $15^{\circ}$. ring defects of glass are visible (cf. arrow) (b-c) AFM image $\left(0.25 \mu \mathrm{m}^{2}\right)$ and corresponding section profile.

(4) $\mathrm{r}-\mathrm{SnO}_{2}$ : annealing of the sputtered $\mathrm{SnO}_{2}$ film on glass has roughened the surface (Fig. 3a) and formed grains with some distribution (18 nm - $39 \mathrm{~nm}$ ) (Fig. 3b-c). The ring defects of glass are still visible (Fig. 3a). The AFM section profile does not evidence sharp variation of heights indicating that grains are not facetted as in the case of the CVD film (Fig. 3c).

(b)

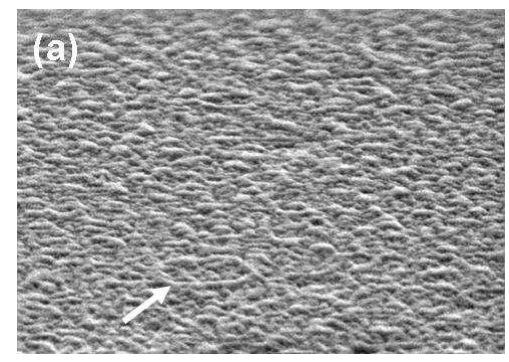

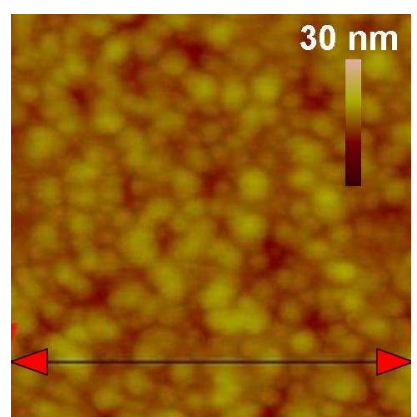

Fig. 3. $\mathrm{r}-\mathrm{SnO}_{2}$ morphology (a) SEM image of a tilted section of $15^{\circ}$. ring defects of glass are still visible (cf. arrow) (b-c) AFM image $\left(0.25 \mu \mathrm{m}^{2}\right)$ and corresponding section profile. 
(5) $\mathrm{R}-\mathrm{SiO}_{2}$ : the sputtering of a silica layer on glass has roughened its surface. Silica coated glass is characterized by a thin structure due to small grains having a diameter which can be as large as a few tens of nanometres. The grains are gathered in clusters which are not well defined (Fig. 4a-c).

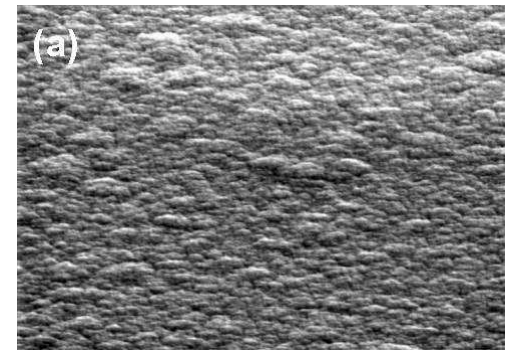

(b)

(c)

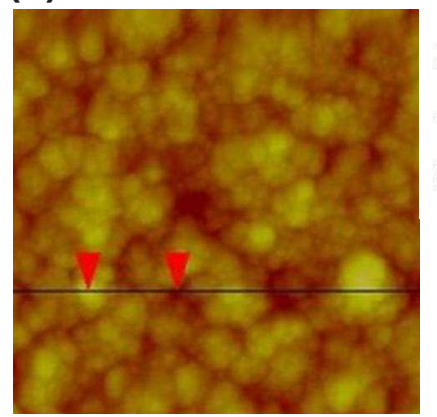

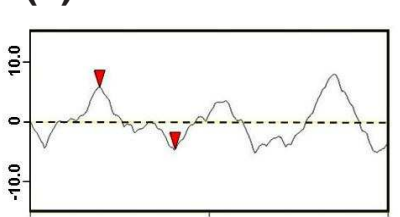

Fig. 4. $\mathrm{R}-\mathrm{SiO}_{2}$ morphology (a) SEM image of a tilted section of $15^{\circ}$ (b -c) AFM image $(0.25$ $\mu \mathrm{m}^{2}$ ) and corresponding section profile.

(6) $\mathbf{R}-\mathrm{Si}_{3} \mathbf{N}_{4}$ : the deposit of a thin layer of silicon nitride on the CVD tin dioxide film has only altered the surface chemistry of the primer. The structure of this substrate is close to the $\mathrm{SnO}_{2} \mathrm{CVD}$ film on glass morphology (Fig. 5a-b) with empty volumes (black features in Fig. 5a) as well as discrete grains having an average size of $25 \mathrm{~nm}$. However, the section profile has changed after the silicon nitride deposition. The height variation is less sharp than that observed in the case of the CVD facetted grains: grains have become larger and more spherical than the CVD tin dioxide grains (Fig. 5c).

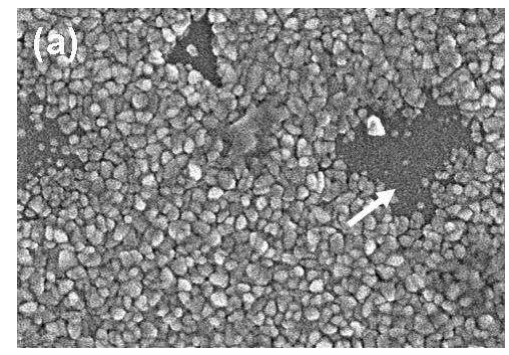

(b)

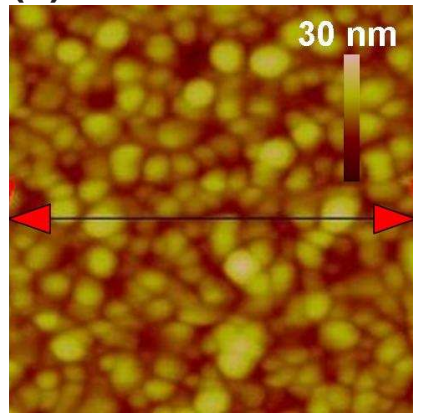

(c)

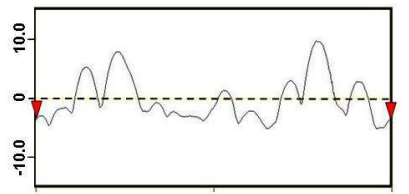

Fig. 5. $\mathrm{R}-\mathrm{Si}_{3} \mathrm{~N}_{4}$ morphology (a) $\mathrm{SEM}$ image: holes are still visible (cf. arrow) (b-c) AFM 
image $\left(0.25 \mu \mathrm{m}^{2}\right)$ and corresponding section profile.

\begin{tabular}{|c|c|c|}
\hline \multicolumn{2}{|c|}{ Substrate for the polymer coating } & $R_{r m s}$ roughness (nm) \\
\hline$(1)$ & glass & 0.8 \\
\hline$(2)$ & $\mathbf{R}-\mathrm{SnO}_{2}$ & 3.0 \\
\hline$(3)$ & $\mathbf{S}-\mathrm{SnO}_{2}$ & 0.8 \\
\hline$(4)$ & $\mathbf{r}-\mathrm{SnO}_{2}$ & $1.65-1.95$ \\
\hline$(5)$ & $\mathbf{R}-\mathrm{SiO}_{2}$ & 2.4 \\
\hline$(6)$ & $\mathbf{R}-\mathrm{Si}_{3} \mathbf{N}_{4}$ & 3.1 \\
\hline
\end{tabular}

Table 1: $R_{r m s}$ roughness of substrates for the polymer coating. In the presentation, the roughest coatings are denoted $R$ ( $R$ for Rough): $R-S_{3} N_{4}, R-S n O_{2}$ and $R-S i O_{2}$, the smoothest coating is denoted $\mathrm{S}$ ( $\mathrm{S}$ for $\mathrm{Smooth}$ ); $\mathrm{S}-\mathrm{SnO}_{2}$ and the intermediate primer roughness between $\mathrm{S}-\mathrm{SnO}_{2}$ and $\mathrm{R}-\mathrm{SnO}_{2}$ is denoted $\mathrm{r}$ ( $\mathrm{r}$ for rough).

\section{Results and discussion}

\subsection{Organic layer stabilization by tin dioxide}

A first step was to assess the anchoring function of the tin dioxide for the polymer coating. The scratch resistance of $\mathrm{R}-\mathrm{SnO}_{2}$ and glass without primer are compared after the polymer deposition.

\subsubsection{Morphology of polymer on $\mathrm{R}-\mathrm{SnO}_{2}$ and glass}

At the AFM scale, the morphology of polymer coatings is only described by the dispersion of the PMMA spheres on surfaces. PMMA spheres are mainly individual and rather well distributed on $\mathrm{R}-\mathrm{SnO}_{2}$ (Fig. 6a), while forming large clusters of variable sizes on glass (Fig. 6b). 
(a)

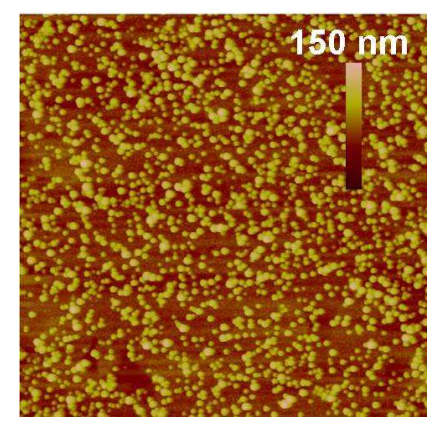

(b)

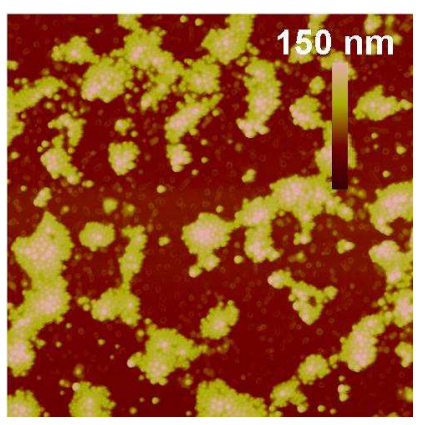

Fig. 6. AFM image $\left(25 \mu \mathrm{m}^{2}\right)$ of organic coating on (a) $\mathrm{R}-\mathrm{SnO}_{2}$ and (b) glass.

\subsubsection{Friction behaviour of polymer on $\mathrm{R}-\mathrm{SnO}_{2}$ and glass}

Fig. 7 compares the friction behaviour of glass and $\mathrm{R}-\mathrm{SnO}_{2}$ after the polymer deposition. The polymer layer has a lubricant effect on both substrates: the friction averaged on the first cycle is low $\left(\mu=0.07\right.$ for glass and $\mu=0.11$ for $\mathrm{R}-\mathrm{SnO}_{2}$ ) compared to the friction between silica and glass $(\mu \approx 0.6-0.7)$ or $\mathrm{SnO}_{2}(\mu \approx 0.55-$ 0.6). However, this lubricant effect disappears almost instantaneously on glass as confirmed by the substrate damage within 2 cycles (i.e. $32 \mathrm{~mm}$ ). A steep rise in friction is recorded and a friction coefficient of 0.6 is quickly achieved.

The lubricant effect is dramatically stabilized when the $\mathrm{SnO}_{2}$ primer is present. Before substrate damage, the friction of the polymer-coated $\mathrm{R}-\mathrm{SnO}_{2}$ evolves in two stages. The first one is characterized by a low friction $(\mu \leq 0.1)$. The second stage is described by a progressive increase in friction $(0.1 \leq \mu \leq 0.2)$ ending with a sudden jump in friction accompanied by damage (substrate cracking) when $\mu$ exceeds 0.3 . The cumulated sliding distance to substrate damage quantifies the scratch resistance of the coated glasses. 


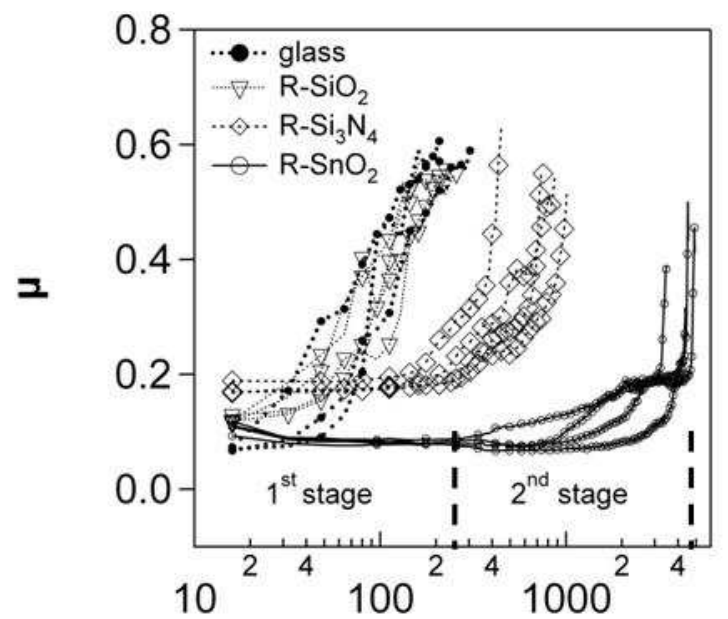

Cumulated sliding distance $(\mathrm{mm})$

Fig. 7. Evolution of $\mu$ with the cumulated sliding distance when the polymer is deposited on (-•--) glass, (-๑-) $\mathrm{R}-\mathrm{SiO}_{2},(-\diamond-) \mathrm{R}-\mathrm{Si}_{3} \mathrm{~N}_{4},(-\ominus-) \mathrm{R}-\mathrm{SnO}_{2} \cdot \mu$ averaged on the first cycle is: 0.12 for $\mathrm{R}-\mathrm{SiO}_{2}$, and 0.18 for $\mathrm{R}-\mathrm{Si}_{3} \mathrm{~N}_{4}$.

\subsubsection{Wear track analysis}

\subsubsection{Infrared microscopy results}

To understand the stabilization phenomenon of the organic layer by the primer, the evolution of the amount of the polymer due to the mechanical stress was investigated on polymer-coated $\mathrm{R}-\mathrm{SnO}_{2}$ and polymer-coated glass before substrate damage. Infrared spectra from wear tracks obtained after short friction tests duration (one pass, 1 and 2 cycles) on polymer-coated glass are reported in Fig. 8. The intensity of $v_{C H 2}$ and $v_{C=O}$ can increase or significantly be reduced from one point to the other in the track after one pass, but these bands are no longer detected after 1 cycle wherever the location in the track. A similar trend is observed when the friction test is repeated at different locations on the coating.

In the presence of tin dioxide, the evolution of $\mathrm{V}_{\mathrm{CH} 2}$ is difficult to follow as the signal to noise ratio recorded before friction is weaker than the one recorded on glass (not shown). Therefore, infrared results were only focused on the evolution of the 
carbonyl band intensity of PMMA, i.e. within the first 2 cycles and when $\mu$ has reached a given value in each stage of the friction evolution. As shown in Fig. 9, the $v_{C=O}$ intensity remains stable within the first 2 cycles and the stretching band is detected as long as $\mu$ does not exceed 0.2 .

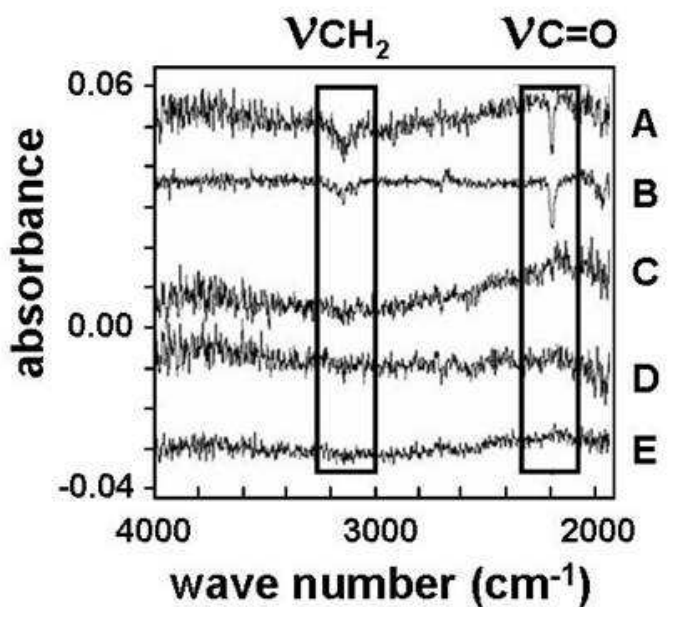

Fig. 8. Reflection infrared spectra from the polymer-coated glass before friction and from the wear tracks as a function of the cumulated sliding distance. $(A)$ before friction (B) after one pass $(8 \mathrm{~mm})$ at the $1^{\text {st }}$ location in the track $(B)$ after one pass at the $2^{\text {nd }}$ location in the track (C) after 1 cycle $(16 \mathrm{~mm})$ at the $1^{\text {st }}$ or $2^{\text {nd }}$ location in the track (D) after 2 cycles $(32 \mathrm{~mm})$ at the $1^{\text {st }}$ or $2^{\text {nd }}$ location in the track. Measurements at two different locations in the track are different after one pass ( $1^{\text {st }}$ and $2^{\text {nd }}$ point) and become similar after 1 and 2 cycles ( $1^{\text {st }}$ or $2^{\text {nd }}$ point). 


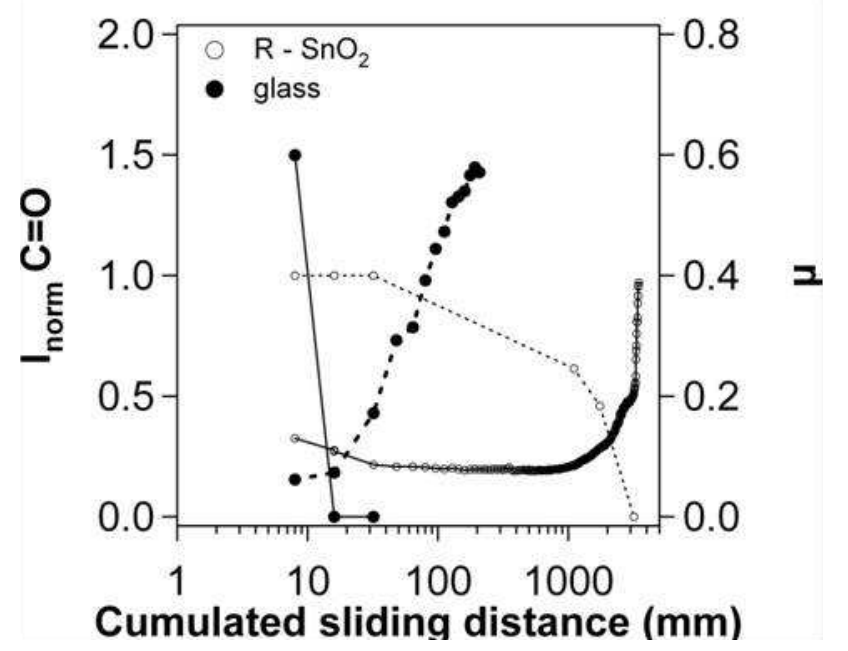

Fig. 9. Evolution of the normalized $v_{C=O}$ intensity with the cumulated sliding distance when the polymer is deposited on (-•-) glass, and (-०-) $\mathrm{R}-\mathrm{SnO}_{2}$ (left vertical axis). Evolution of $\mu$ with the cumulated sliding distance when the polymer is deposited on (--•--) glass and ($\ominus-) \mathrm{R}-\mathrm{SnO}_{2}$ (right vertical axis).

\subsubsection{Nomarski optical microscopy and AFM results}

\subsection{Initial stage of friction: onset of wear on glass}

A heterogeneous build up of polymer is observed after one pass on the polymer-coated glass. Aggregates with sizes as large as $20 \mu \mathrm{m}$ have formed (Fig. 10a). Their sizes are larger than those formed during the deposit and are made of flattened PMMA spheres which have coalesced (Fig. 11a). The heterogeneous distribution of the polymer in the contact as well as the large dispersion in the aggregate sizes clarifies the infrared results after one pass, i.e. the decrease or the increase in the $v_{C=O}$ intensity at different locations in the track. There is a strong variation of the amount of polymer at different locations in the wear track and the size of the rectangular slit in the mask used to select areas is not large enough to average these variations. After 1 cycle, the density of clusters as well as their size decreases, and the polymer is only evidenced by AFM after 2 cycles. At this stage which precedes glass damage, polymer fragments are aligned in the sliding direction 
covering about half of the wear track (Fig. 11c). The polymer alignment starts in the center of the track where the pressure is maximal [19].

\subsection{Initial stage of friction: onset of lubrication on $\mathrm{R}-\mathrm{SnO}_{2}$}

After one pass on the polymer-coated $\mathrm{R}-\mathrm{SnO}_{2}$, aggregates have not formed (Fig. 10b) as on glass but infrared microscopy confirms the presence of the polymer which masks the tin oxide grain boundaries (Fig. 11b). AFM observation and infrared results suggest that the polymer forms a continuous film compared to the clusters built up on glass. The film starts to coalesce in the center of the track and already covers about half of the track after one pass. After 2 cycles, the film becomes more homogeneous. Regions which were free of PMMA are gradually covered by the polymer, suggesting a large plastic deformation of the film. When $\mu$ has reached a stable value in the first stage of the friction evolution, the film is still present in the track, as confirmed by infrared results and homogeneously distributed. The film is very smooth, as evidenced by the flat section (Fig. 11e) and has expanded towards edges to cover the whole track.

(a)

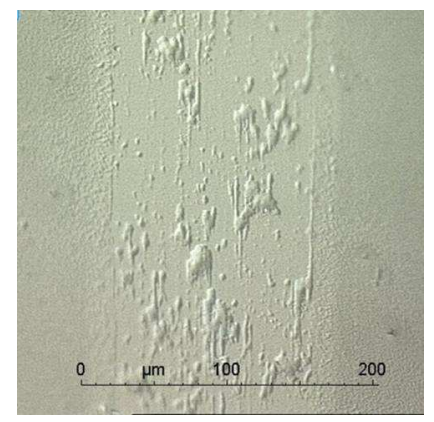

(b)

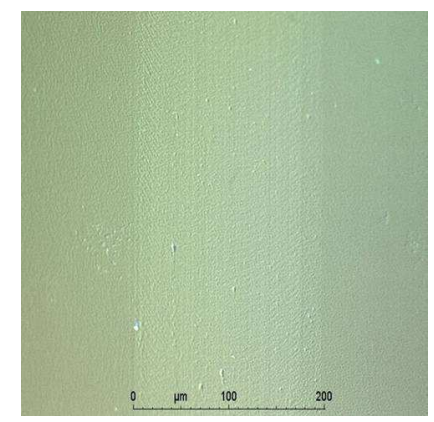

Fig. 10. Optical image of the wear track after one pass on (a) polymer-coated glass and (b) polymer-coated $\mathrm{R}-\mathrm{SnO}_{2}$. 
(a)

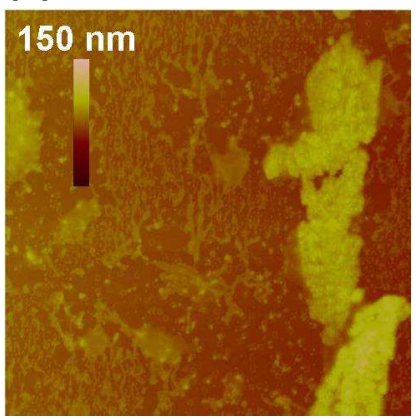

(c)

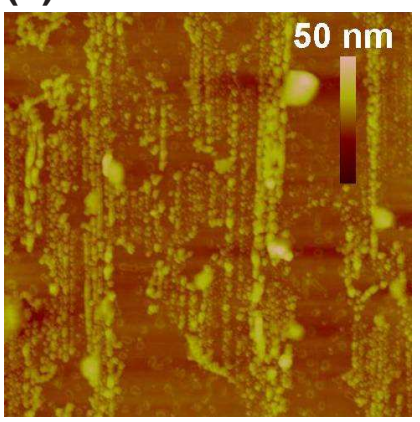

(b)

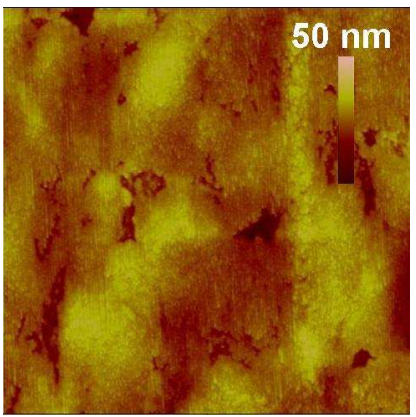

(d)

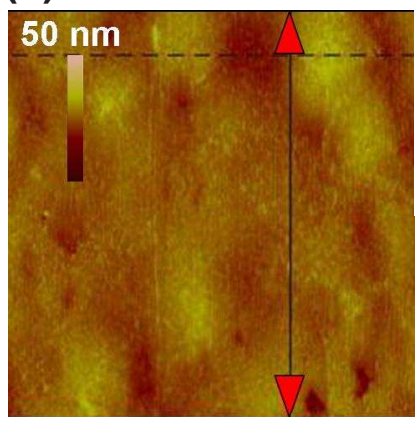

(e)

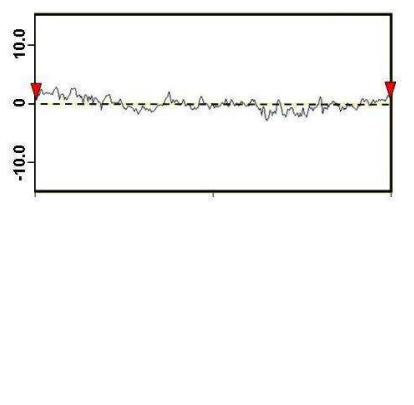

Fig. 11. AFM image $\left(25 \mu \mathrm{m}^{2}\right)$ of wear tracks (a) after one pass on polymer-coated glass (b) after one pass on polymer-coated $\mathrm{R}-\mathrm{SnO}_{2}$ (c) after 2 cycles on polymer-coated glass, in half of the track ( $\mathrm{d}-\mathrm{e}$ ) when $\mu=0.085$ on polymer-coated $\mathrm{R}-\mathrm{SnO}_{2}$ and the corresponding section profile.

\subsubsection{Discussion}

Without primer, the fast disappearance of the carbonyl stretching band of PMMA and the $\mathrm{CH}_{2}$ stretching bands of PE in infrared microscopy evidences a weak adhesion of the polymer on glass. This induces a high mobility of the polymer under the mechanical stress. Large aggregates are built up and are quickly removed from the contact, resulting in the absence of scratch resistance. On the other hand, the persistence of the PMMA stretching band $v_{C=O}$ over large sliding distances on tin dioxide-coated glass highlights a strong adhesion of the organic layer on the primer. The mobility of the polymer is then considerably reduced and a continuous film is formed under the mechanical stress. This leads to a significant scratch resistance of 
the coated glass. Glass and $\mathrm{R}-\mathrm{SnO}_{2}$ have both acidic surface $\mathrm{OH}$ groups which are effective sites for organic adsorbates [23]. However, the strength of Brönsted acidity of hydroxyl groups is increased by the metallic cation, the presence of which enhances the $\mathrm{O}-\mathrm{H}$ bond polarisation as well as results in strong Lewis acid sites [13]. Therefore, the basic carbonyl oxygen in the ester groups of PMMA can coordinate by $\mathrm{H}$-bonding with the acid sites more strongly on tin dioxide than on glass [24]. In the specific case of the non polar PE which is reported to adhere weakly on glass [13], its C-C double bonds may coordinate with the Lewis sites. However, according to the slow decrease in the $v_{C=O}$ intensity, the strong adhesion of the organic coating on $\mathrm{R}-$ $\mathrm{SnO}_{2}$ does not prevent its progressive wear. Moreover, the presence of some polymer in the contact is not excluded when the $v_{C=O}$ band is no longer detected at $\mu$ $=0.2$. This assumption is based on the optical observation that cracks only initiate at a higher value of friction $(\mu>0.3)$. Friction tests also pointed out that $\mathrm{R}-\mathrm{SnO}_{2}$ without polymer has no scratch resistance (not shown). From wear track analysis and imaging, it is then concluded that before damage, the tribological behaviour of the polymer-coated $\mathrm{R}-\mathrm{SnO}_{2}$ can be ascribed to the progressive wear of the organic film leading first to a silica-polymer contact (first stage, $\mu \leq 0.1$ ) and then to a contact between silica and $\mathrm{SnO}_{2}$ with some patches of polymer film (second stage, $0.1 \leq \mu \leq$ 0.2 and $\mu>0.3$ ). Damage occurs when there is no longer enough polymer in the contact to protect the oxide $(\mu>0.3)$. The friction value observed in the first stage is higher than those observed for polyethylene-based coating dispersions in dual coatings $(\mu \approx 0.03)[1]$. This result may be explained by the addition of PMMA which is used for a suitable label adhesion [25-27]. The suggestion about the nature of the contact in the second stage is supported by the observation of lower friction values on hot-end coated glass bottles $[1,28]$ or $\mathrm{SnO}_{2}$-coated flat glass when surfaces are 
contaminated with organic residues $[28,29]$. The high friction recorded for the silica$\mathrm{SnO}_{2}$ contact without surface contaminants $(\mu \approx 0.55-0.6)$ is considerably reduced due to their lubricant effect [30-32].

\subsection{Respective roles of roughness and surface chemistry of tin dioxide in the organic layer stabilization}

The deposition of a crystallized tin dioxide film on glass has roughened the surface, modified the surface chemistry as well as the surface morphology. In order to identify the parameters which are responsible for the stabilization of the polymer layer, the effect of roughness and surface chemistry was assessed on flat glass with different coatings.

\subsubsection{Morphology of polymer on $\mathrm{S}-\mathrm{SnO}_{2}, \mathrm{r}-\mathrm{SnO}_{2}, \mathrm{R}-\mathrm{SiO}_{2}$ and $\mathrm{R}-\mathrm{Si}_{3} \mathrm{~N}_{4}$}

The polymer aggregates on $\mathrm{S}-\mathrm{SnO}_{2}$ and $\mathrm{R}-\mathrm{SiO}_{2}$. Clusters are of large variable size on $\mathrm{S}-\mathrm{SnO}_{2}$, as in the case of glass and smaller on $\mathrm{R}-\mathrm{SiO}_{2}$. The good wetting of the polymer previously observed on $\mathrm{R}-\mathrm{SnO}_{2}$ is similar on $\mathrm{R}-\mathrm{Si}_{3} \mathrm{~N}_{4}$ and $\mathrm{r}-$ $\mathrm{SnO}_{2}$. A large dispersion in shape and cluster sizes is only noticed for $\mathrm{S}-\mathrm{SnO}_{2}$, the surface of which has topographical and/or chemical heterogeneities (rings) unlike R$\mathrm{SiO}_{2}, \mathrm{R}-\mathrm{Si}_{3} \mathrm{~N}_{4}$ and $\mathrm{r}-\mathrm{SnO}_{2}$. The variable size and shape of aggregates on the smoothest tin dioxide may be due to a pinning effect by these surface defects which can influence the polymer wetting [33-35].

\subsubsection{Friction behaviour of polymer on $\mathrm{S}-\mathrm{SnO}_{2}, \mathrm{r}-\mathrm{SnO}_{2}, \mathrm{R}-\mathrm{SiO}_{2}$ and $\mathrm{R}-\mathrm{Si}_{3} \mathrm{~N}_{4}$}

The friction behaviour of $\mathrm{R}-\mathrm{SiO}_{2}$ and $\mathrm{R}-\mathrm{Si}_{3} \mathrm{~N}_{4}$ is reported in Fig. 7, and Fig. 12 compares the friction results for $\mathrm{S}-\mathrm{SnO}_{2}$ and $\mathrm{r}-\mathrm{SnO}_{2}$, after polymer deposition. 
Whatever the coated glass, the friction averaged on the first cycle is low compared to the friction between silica and glass or $\mathrm{SnO}_{2}$ (cf. 3.1.2). $\mathrm{R}-\mathrm{SiO}_{2}$ behaves like glass. Friction on $\mathrm{R}-\mathrm{Si}_{3} \mathrm{~N}_{4}$ evolves as $\mathrm{R}-\mathrm{SnO}_{2}$, but each stage is associated with higher friction values (first stage with $\mu \leq 0.18$ and second stage with $0.18 \leq \mu \leq 0.3$ ). The general trend of friction on $\mathrm{S}-\mathrm{SnO}_{2}$ and $\mathrm{r}-\mathrm{SnO}_{2}$ is similar: the friction averaged on the first cycle remains stable on a given sliding distance and ends with a steep increase in $\mu$. Optical examination of wear tracks shows that the polymer does not protect $\mathrm{R}-\mathrm{SiO}_{2}$ and $\mathrm{R}-\mathrm{Si}_{3} \mathrm{~N}_{4}$ as both substrates are damaged after one pass. Damage begins at the center of the track on $\mathrm{R}-\mathrm{SiO}_{2}$ similarly to glass and cracks initiate on $\mathrm{R}-\mathrm{Si}_{3} \mathrm{~N}_{4}$ as observed in the case of $\mathrm{R}-\mathrm{SnO}_{2}$. Unlike $\mathrm{R}-\mathrm{SiO}_{2}$ and $\mathrm{R}-\mathrm{Si}_{3} \mathrm{~N}_{4}$, the polymer has a lubricant effect on $\mathrm{S}-\mathrm{SnO}_{2}$ and $\mathrm{r}-\mathrm{SnO}_{2}$ which disappears when $\mu$ exceeds 0.3 , as confirmed by cracks initiation. In spite of the large scratch resistance dispersion on both coated glasses, the lubricant effect is stabilized over larger cumulated sliding distances on $\mathrm{r}-\mathrm{SnO}_{2}$. The scratch resistance can double on $\mathrm{r}$ $\mathrm{SnO}_{2}$ as compared with the highest scratch resistance recorded on $\mathrm{S}-\mathrm{SnO}_{2}$.

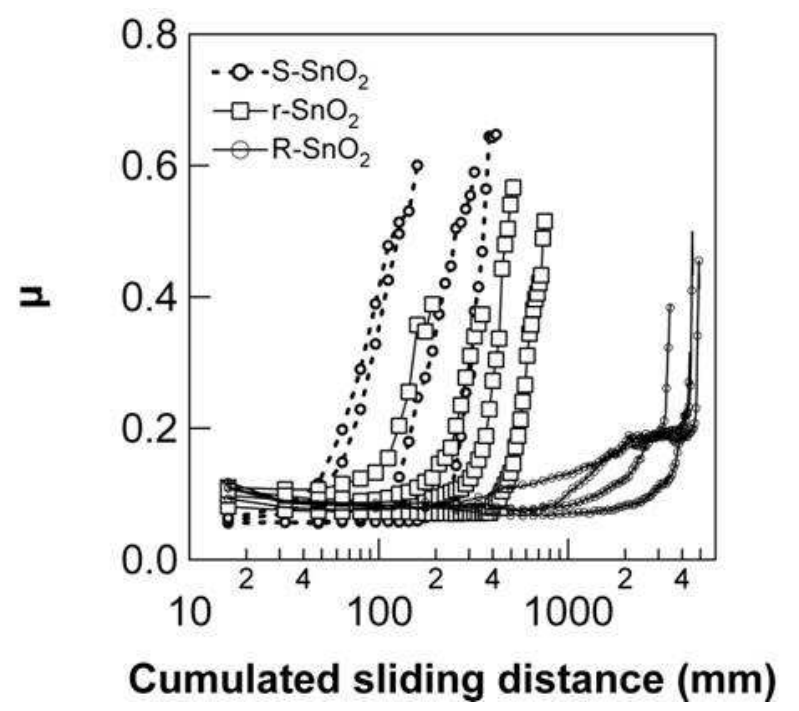

Fig. 12. Evolution of $\mu$ with the cumulated sliding distance when the polymer is deposited on (--o--) S- $\mathrm{SnO}_{2},(-\square-) \mathrm{r}-\mathrm{SnO}_{2}$ and $(-\ominus-) \mathrm{R}_{-} \mathrm{SnO}_{2} . \mu$ averaged on the first cycle is: 0.06 for $\mathrm{S}-\mathrm{SnO}_{2}$ and 0.09 for $\mathrm{r}-\mathrm{SnO}_{2}$. 


\subsubsection{Discussion}

The suppression of the strong acid-base interactions between CVD $\mathrm{SnO}_{2}$ films and the polymer by a silicon nitride deposit has instantaneously inhibited the anchoring function of $\mathrm{SnO}_{2}$. These results suggest that the polymer-oxide interface plays a role in the stabilization of the organic layer, insofar as the $R_{r m s}$ roughness of the surface was preserved. Glass roughening by a silica layer has no impact on the polymer anchoring, but the polymer stabilization by a rougher glass is not excluded. $\mathrm{S}-\mathrm{SnO}_{2}$ and $\mathrm{r}-\mathrm{SnO}_{2}$ are both able to anchor the polymer on surface, but the scratch resistance is improved when the tin dioxide roughness increases, suggesting that the primer roughness also contributes to the stabilization of the polymer layer. The highest scratch resistance is obtained on the roughest tin dioxide and this trend agrees well with the suggestion of Pantano et al. [16] about the mechanical anchoring function of the primer for organic coatings. Moreover $\mathrm{CVD} \mathrm{SnO}_{2}$ films differ from the smoother primers by their sharpened roughness. Therefore, two possible parameters can control the large plastic deformation of PMMA spheres leading to the lubricating film, i.e. the sharpness of $\mathrm{SnO}_{2}$ roughness and shear due to the strong adhesion of the polymer on the primer. A schematic view of the film formation mechanism is presented in Fig. 13. Such a cooperative effect has been also reported in the case of electrically conductive polymers deposited on oxidized metals such as titanium oxides [36]. The weak adhesion of polymer noticed on the pure metal is strongly enhanced after the metal pre-oxidation which simultaneously induces a change in surface chemistry as well as an increase in the roughness of the surface. 


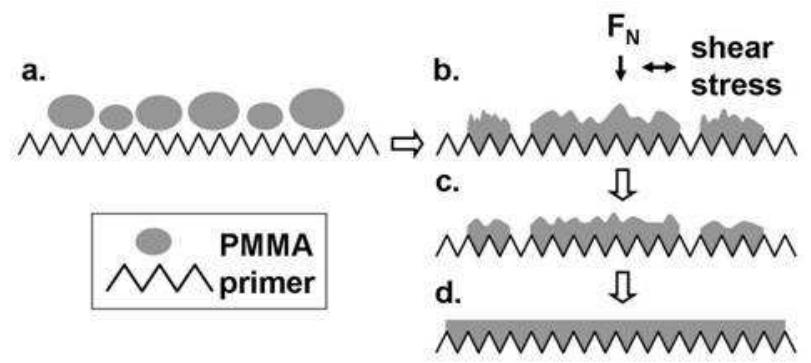

Fig. 13. Schematic view of the polymer film formation mechanism under friction (a) PMMA spheres dispersion on the $\mathrm{SnO}_{2}$ primer, the roughness of which is due to facetted grains (b) spheres flattening and coalescence of flattened spheres under the compressive and shear stresses leading to a lubricating film which coexists with some patches of film (c-d) expansion of the film to cover the whole contact: the film becomes smoother.

\section{Conclusion}

The stabilization of organic coatings by CVD $\mathrm{SnO}_{2}$ films (primer) resulting in glass bottle lubrication was investigated on flat glass with a mixture of PE and PMMA spheres. Friction tests in air on bare glass and with the primer confirm that the stabilization of the polymer over large sliding distances is only achieved in presence of $\mathrm{SnO}_{2}$. The study evidences the strong adhesion of the polymer on $\mathrm{SnO}_{2}$ through the persistence of the PMMA stretching band $v_{C=O}$ on significant sliding distances, leading to the build up of a continuous film. Weak adhesion on bare glass results in fast disappearance of $v_{C=O}$ and the build up of large aggregates which are quickly removed from the contact. The film and aggregates are formed by coalescence of squashed PMMA spheres. The role of roughness and surface chemistry in the anchoring function of the $\mathrm{CVD} \mathrm{SnO}_{2}$ films was tested. The surface chemistry alteration and glass roughening suppress the lubricant effect. By modulating the primer roughness, it was demonstrated that the scratch resistance is highly correlated to this roughness. The study shows that the interplay between roughness and surface chemistry of $\mathrm{SnO}_{2}$ is necessary for stabilization of the polymer into a lubricating film. 


\section{Acknowledgements}

The authors thank Saint-Gobain Recherche for the interactive discussions and financial support.

\section{References}

[1] R.D. Southwick, J.S. Wasylyk, G.L. Smay, J.B. Kepple, E.C. Smith, B.O. Augustsson, Thin Solid Films 77 (1981) 41.

[2] M.W. Davis, G.L. Smay, J.S. Wasylyk, Am. Ceram. Soc. Bull. 66 (1987) 1627.

[3] T. Takeuchi, I. Doteshita, S. Asami, Surf. Interface Anal. 36 (2004) 1133.

[4] H.P. Williams, Glass Technol. 16 (1975) 34.

[5] A.M.B. van Mol, Y. Chae, A.H. McDaniel, M.D. Allendorf, Thin Solid Films 502 (2006) 72.

[6] S.M. Lee, D.L. Kim, H.J. Youn, K.S. Hong, Jpn. J. Appl. Phys. 39 (2000) 407.

[7] J. Giersberg, G. Eisen, P. Marchesi, Int. Glass J. 104 (1999) 38.

[8] Y. Chae, W.G. Houf, A.H. McDaniel, J. Troup, M.D. Allendorf, J. Electrochem. Soc. 151 (2004) C527.

[9] A.M.B. van Mol, G.R. Alcott, M.D. Allendorf, Am. Ceram. Soc. Bull. 84 (2005) 37. [10] X. Drujon, Glass Int. 30 (7) (2007) 24.

[11] F. Geotti-Bianchini, M. Preo, Glastech. Ber. Glass Sci. Technol. 72 (1999) 341.

[12] J.D.J. Jackson, B. Rand, H. Rawson, Thin Solid Films 77 (1981) 5.

[13] G.L. Smay, Glass Technol. 26 (1985) 46.

[14] G.L. Smay, J. Am. Ceram. Soc. 71 (1988) C217.

[15] A. Bhargava, F. Wang, B. Wood, G. Higginbotham, I. Gentle, Surf. Interface Anal. 29 (2000) 663.

[16] C.G. Pantano, V.J. Bojan, G. Smay, Glass Researcher 9 (1999) 12. 
[17] C.G. Pantano, Ceram. Eng. Sci. Proc. 22 (2001) 137.

[18] R.Y. Korotkov, P. Ricou, A.J.E. Farran, Thin Solid Films 502 (2006) 79.

[19] K.L. Johnson, Contact Mechanics, Cambridge University Press, 1985.

[20] Y.S. Choe, J.H. Chung, D.S. Kim, G.H. Kim, H.K. Baik, Mater. Res. Bull. 34 (1999) 1473.

[21] M.D. Allendorf, Electrochem. Soc. Interface 10 (2001) 34.

[22] W.C. LaCourse, H. Black, Glass Researcher 1 (2) (1991) 1.

[23] S. Takeda, M. Fukawa, Mater. Sci. Eng. B 119 (2005) 265.

[24] F.M. Fowkes, D.W. Dwight, D.A. Cole, J. Non-Cryst. Solids 120 (1990) 47.

[25] B. Bhushan, Z. Burton, Nanotechnology 16 (2005) 467.

[26] N.S. Tambe, B. Bhushan, Nanotechnology 15 (2004) 1561.

[27] N.S. Tambe, B. Bhushan, Ultramicroscopy 105 (2005) 238.

[28] W.E. Swindlehurst, B. Cantor, Glass Technol. 19 (1978) 14.

[29] A.S. Sanyal, J. Mukerji, Glass Technol. 25 (1984) 214.

[30] F. Geotti-Bianchini, Rivista della Staz. Sper. Del Vetro 30 (2000) 93.

[31] F. Geotti-Bianchini, M. Preo, C.G. Pantano, Glass Technol. 43 (2002) 147.

[32] A. Hattori, J. Non-Cryst. Solids 218 (1997) 196.

[33] M. Yamanaka, A. Okada, A. Kawai, J. Vac. Sci. Technol. B 22 (2004) 3525.

[34] T. Cubaud, M. Fermigier, P. Jenffer, Oil Gas Sci. Technol. 56 (2001) 23.

[35] T. Cubaud, M. Fermigier, J. Colloid Interface Sci. 269 (2004) 171.

[36] K. Idla, O. Inganäs, M. Strandberg, Electrochim. Acta 45 (2000) 2121. 